\title{
Utilization of Biocoke as Raw Material for Carbon Anode Production
}

\author{
Xianai Huang*, Duygu Kocaefe, Yasar Kocaefe \\ UQAC Chair on Industrial Materials (CHIMI) \\ University Research Centre on Aluminium (CURAL), University of Quebec at Chicoutimi \\ 555 Boulevard de l'Université, Chicoutimi, Québec, G7H 2B1, Canada
}

\begin{abstract}
Calcined biocokes were successfully produced from wood precursors through pyrolysis at high temperature $\left(1200{ }^{\circ} \mathrm{C}\right)$. The resultant material mimics the microstructure of calcined petroleum coke and presents high carbon content, making them potential raw material for carbon anodes used for the production of aluminum. The properties of these biocokes that are important for anode production such as real density, crystalline length, carbon content, particle surface area, and chemical surface characteristics, were determined using gas pycnometer, energy dispersive X-ray spectroscopy, BET, and FTIR. The microstructure and the morphology of biocokes were characterized using SEM. The degree of structural disorder in the biocokes was evaluated by Raman spectroscopy. The objective of this work is to study how the partial replacement of calcined petroleum coke by a biocoke affects the properties of corresponding laboratory anodes. Also, an anode without any biocoke was fabricated as a standard for comparison with those made with the addition of biocoke. Tests were carried out on green anodes, and the core samples taken from them were characterized in green state and after baking according to the appropriate standards. Experimental results show that the replacement of 3\% of petroleum coke by biocoke in the fine fraction results in anodes with properties similar to those of the standard anodes.
\end{abstract}

Keywords: biocoke, carbon anode, GHG emissions, $\mathrm{CO}_{2}$ and air reactivities, petroleum coke

\section{Introduction}

Carbon anode plays multiple roles during the electrolytic production of aluminum. It conducts electrical current and participates in the reduction process. It is the source of carbon for reaction with oxygen coming from the alumina, and it helps reduce alumina to metallic aluminum. The theoretical carbon consumption is $0.334 \mathrm{~kg} \mathrm{C} / \mathrm{kg} \mathrm{Al}$; however, the actual consumption is usually above $0.4 \mathrm{~kg} \mathrm{C} / \mathrm{kg} \mathrm{Al}$ due to secondary reactions. Because of its importance in electrolysis, stringent requirements in electrical, physical, 
mechanical, and chemical properties of anodes are needed to ensure high productivity and efficiency in modern smelters.

The substantial dependence on carbon and electricity makes the electrolytic aluminum production process a major greenhouse gas (GHG) emitter. All of the carbon consumed in the electrolysis cell is eventually released to atmosphere as mainly $\mathrm{CO}_{2}$ (plus some $\mathrm{CO}$ ). In Canada alone, annual $\mathrm{CO}_{2}$ emission due to carbon anode consumption in smelters is about $1.2 \times 10^{6}$ tonnes. In order to find a solution for the reduction of the impact of this process on environment, the UQAC (University of Quebec at Chicoutimi) Research Chair on Industrial Materials (CHIMI) initiated a research program to examine the technical feasibility of partial replacement of petroleum coke by renewable bio-carbon materials in making anodes. .Bio-carbon refers to carbon sources originating from recent biological materials. Combustion of bio-carbon also releases $\mathrm{CO}_{2}$; however, $\mathrm{CO}_{2}$ released by the combustion of bio-material from renewable sources is balanced by the $\mathrm{CO}_{2}$ absorbed during its growth period. Since the duration of this natural carbon cycle is relatively short compared to that of fossil carbon, $\mathrm{CO}_{2}$ originating from renewable bio-carbon materials is considered as GHG neutral.

The properties of bio-carbon materials have been extensively studied [1-7]. A number of studies have been carried out to determine the effect of incorporating a bio-carbon material in anode production on the chemical, physical, and structural properties of the resultant anode quality [8-13]. Utilization of bio-carbon as raw material to make anodes is still challenging despite these research and development efforts. The major challenge arises from the fact that even a small amount of bio-carbon material incorporation results in a significant reduction in resultant anode quality. Hence, this limits the bio-material utilization because of not being able to maintain the resultant anode quality suitable for electrolysis cell operation.

Recent experimental studies conducted at UQAC showed that solid bio-carbon (biocoke) displays an anisotropic and lamellar structure similar to that of petroleum coke [14], and the results allowed to establish a relationship between the characteristics of the solid bio-carbon structures and their wettability by coal tar pitch $[15,16]$. This helped develop a number of criteria for choosing suitable pitches to attain good wettability between them and the bio-carbon, which would limit the adverse impact of bio-carbon addition on anode quality [15]. The properties of bio-carbon was further modified via high temperature calcination [16]. This increased the carbon content and the crystalline length of bio-carbon and enhanced its suitability for anode fabrication.

It was also identified that one of the detrimental effects of bio-carbon on anode quality originates from its high porosity [17]. It is hypothesized that the reduction in anode quality is due to the dispersion of highly 
reactive carbonaceous material from bio-material in the resultant anode. It leads to increase in the reactivity of anode with $\mathrm{CO}_{2}$ and air and reduction in anode strength. To overcome this challenge, it is proposed to use fine bio-carbon particles to eliminate its large pores prior to adding it into anodes.

In this work, the performance of biocoke in terms of structure and chemical and physical properties was examined. The effect of heating rate on its real density was evaluated. Anodes were produced and characterized to determine the impact of biocoke particle size and percent added on the mechanical strength, chemical reactivity, and electrical resistivity of the resultant anodes. A novel anode fabrication recipe was developed for the partial replacement of petroleum coke by fine biocoke particles.

\section{Experimental}

\subsection{Materials}

For the fabrication of anodes, industrial raw materials were used: one type of calcined petroleum coke, one type of coal tar pitch, and recycled carbon materials that are required in the recipe. .Biocokes were produced from raw wood that was received in the form of chips. A biochar, pyrolyzed at $425{ }^{\circ} \mathrm{C}$ and received from an industrial partner, was also included in the study.

\subsection{Calcination of biocoke}

Table 1 shows the calcination conditions for all of the materials used in the study. In the first part of this work, trials were conducted to examine the impact of the maximum temperature and the heating rate during calcination on the properties of biocokes produced. Two temperatures and five different heating rates were investigated. The same raw biomass material (wood) was used for the production of biocokes BCO-1 to BCO-4. A bio-char which was pyrolyzed to $425^{\circ} \mathrm{C}$ was also considered for comparison (BCA). In one case, this bio-char was used as the raw material and calcined to $1200^{\circ} \mathrm{C}(\mathrm{BCO}-5)$. Table 1 also gives information on the petroleum coke used.

For this part, the calcination process was carried out in a thermogravimetric analyzer with induction heating (TGA induction). The sample was put in a carbon crucible which was supported by metal wires and suspended from a balance to measure the weight loss of the sample during calcination. Nitrogen was used as the carrier gas to protect the sample in the TGA during induction heating. The nitrogen enters the TGA from the bottom. The real densities of the bio-cokes produced with the TGA were measured by a helium pycnometer. 
In the second part of the study, one biocoke (BCO-1) was chosen for anode production. This required large amounts of biocoke addition to anodes, and biocoke for this purpose was produced using a lab furnace ( $F$ in Table 1) using the same calcination conditions as the ones in the TGA. The large sample was placed in a container that was surrounded by filler coke (calcined petroleum coke used for protection).

Table 1 Materials used in the study and their calcination conditions

\begin{tabular}{|c|c|c|c|c|}
\hline $\begin{array}{c}\text { Coke sample } \\
\text { no. }\end{array}$ & Coke name & $\begin{array}{c}\text { Maximum temperature } \\
\left({ }^{\circ} \mathrm{C}\right)\end{array}$ & $\begin{array}{c}\text { Heating rate } \\
\left({ }^{\circ} \mathrm{C} / \mathrm{min}\right)\end{array}$ & Equipment \\
\hline BCA & Bio-char & 425 & - & (as received) \\
\hline BCO1 & Biocoke & 1200 & 0.2 & TGA and F* \\
\hline BCO2 & Biocoke & 1200 & 1 & TGA \\
\hline BCO3 & Biocoke & 1200 & 1.5 & TGA \\
\hline BCO4 & Biocoke & 1200 & 40 & TGA \\
\hline BCO5 & Biocoke & $(425) / 1200$ & 40 & TGA \\
\hline PC & Petroleum coke & $(1200)^{* *}$ & $(\approx 40)^{* *}$ & (as received) \\
\hline
\end{tabular}

* One biocoke was produced in a TGA for comparison with other biocokes. After this biocoke was chosen for anode production, large quantities were produced in a lab furnace (F) using the same baking procedure. **The heating rate and the maximum temperature of the petroleum coke are not available; however, this petroleum coke was produced in a rotary coke calciner and the heating rate and the maximum temperature are usually around these values in such systems.

\subsection{Characterization of bio-coke}

\subsubsection{SEM/EDS microscopy}

To prepare sample surfaces for SEM, unpolished bio-coke sample particles were mounted onto the surface of an aluminum block of $20 \mathrm{~mm} \times 30 \mathrm{~mm}$ using electrically conducting paste. The test pieces were cleaned with a high-pressure gas to remove the surface dust and debris and to provide a stronger attachment to the electrically conducting paste. For electrical conduction, all samples were sputter-coated with a palladium/gold layer $(20 \mathrm{~nm})$ before mounting them onto standard aluminum stubs using the electrically conducting paste. The samples were scanned using a Jeol scanning electron microscope (JSM 6480LV) with a magnification up to $300000 \mathrm{X}$ at the accelerating voltage of $10 \mathrm{kV}$. The distance between the sample and the electron microscope head was $10-25 \mathrm{~mm}$ with a spot size of 40 . The specimen temperature was approximately $20^{\circ} \mathrm{C}$, and the column vacuum was $6.66 \times 10^{4} \mathrm{~Pa}$. Electron micrographs of biocoke produced 
for anode production for two sizes (less than $45 \mu \mathrm{m}$ and $125 \mu \mathrm{m}$ ) were taken. SEM micrographs of the petroleum coke with sizes less than $45 \mu \mathrm{m}$ were also taken for comparison.

\subsubsection{Determination of the surface area by BET method}

The specific surface areas of the biocokes of different sizes ( $<45 \mu \mathrm{m}$ and 1-2 $\mathrm{mm})$ and the petroleum coke $(<45 \mu \mathrm{m})$ were determined by the BET method based on nitrogen adsorption isotherms using a BET equipment (Gemini VII Surface Area and Porosity, Micrometrics). Adsorption and desorption of nitrogen at liquid nitrogen temperature were measured at relative pressure in the range of $0-1$. The Barrett-JoynerHalenda (BJH) method was used to measure the porosity distribution based on the adsorption-desorption data.

\subsubsection{FTIR analysis}

FT-IR can detect different hybridizations of carbon present in $\mathrm{CH}$ bonds and can identify aromatic and aliphatic hydrocarbons. The chemical structures of the calcined petroleum coke and the biocokes were qualitatively examined by FT-IR spectroscopy at room temperature. The main objective was to identify the complementary functionality between pitch and coke. IR spectra were collected in the wave number range of 500-4000 $\mathrm{cm}^{-1}$, and all the spectra were recorded using $4 \mathrm{~cm}^{-1}$ resolution. For each run, 64 scans were performed prior to the Fourier transformation. All the spectra were collected using the KBr technique (the ratio of sample to $\mathrm{KBr}$ was 1:100). The Spectrum version 5.0.1 software was used, and the result was taken as the average of two experiments. The IR spectra for each experimental set were transformed to absorbance spectra.

\subsubsection{Raman spectroscopy analysis}

The degree of structural disorder in carbon structures for biocoke was evaluated by Raman spectroscopy in the spectral region between 900 and $1900 \mathrm{~cm}^{-1}$ which yields the most interesting structural information on carbonaceous materials [18]. The obtained Raman spectra were analyzed using a custom-made leastsquares fitting code. Relevant bands typical of carbonaceous materials [19, 20] were fitted to pseudo-Voigt line shapes, and relative widths and intensities were calculated.

\subsection{Fabrication of laboratory-scale anodes}

Lab-scale anodes were produced to examine the effect of incorporating biocoke into anodes on anode quality. Anodes studied in this work consist of three components: coal tar pitch as the binder, calcined coke (petroleum coke with or without biocoke addition), and recycled carbon materials. The particulate material is called the dry aggregate. Properties of the binding material are important to form anodes with sufficient 
mechanical strength to withstand handling in the industrial process; and coal tar pitch is widely used as the binder for anode formation. Since this work focuses on the effect of biocoke addition on the resultant anode quality, a commercial coal tar pitch was used, and its proportion in the total carbon material was kept constant in all anodes. The respective fractions of different particle sizes in the dry aggregate were prepared based on a typical industrial recipe. A standard anode was produced without biocoke as the reference.

The same biocoke BCO-1 (produced in the lab furnace at $1200{ }^{\circ} \mathrm{C}$ in large quantities) was used in the anodes with biocoke addition. For anodes in which the petroleum coke was partially replaced by biocoke, three percentages were considered. Part of the fine fraction (particle size less than $125 \mu \mathrm{m}$ ) of petroleum coke in the recipe was replaced by biocoke (1\%, 3\%, $5 \%$ in weight) within the same particle size range. To investigate the impact of the particle size of biocoke on the resultant anode quality, one anode was produced by replacing $3 \%$ of petroleum coke by biocoke using finer particles with sizes less than $45 \mu \mathrm{m}$. The binder and dry aggregate proportions including the particle size fractions, that is, the recipe for these anodes were kept the same as the standard anode to allow the direct comparison of experimental results. The only variation was the percentage of biocoke substitution in the anodes and the particle size of the biocoke added.

The measured dry aggregate components were mixed with the molten coal tar pitch at around $170^{\circ} \mathrm{C}$. The paste was compacted in a vibro-compactor for a certain period to form green anodes of about $10 \mathrm{~kg}$ with a rectangular cross-section. The green anodes and cores taken from them have been characterized. Some cores were baked, and further characterization of baked cores was carried out. The details are given in the following section.

\subsection{Characterization of anodes}

The 3D distributions of electrical resistivity in green anodes were determined using the SERMA technology developed by the chair CHIMI.

After the completion of the testing on entire green anodes, core samples ( $\varphi 50 \times 130 \mathrm{~mm})$ were taken from them. The density and the electrical resistivity of the green core samples ( $\varphi 50 \times 130 \mathrm{~mm})$ were measured based on the standards ASTM D5502-00 (2015) and ASTM D6120-97 (2012), respectively. The green cores were baked following a typical industrial baking procedure. The density, electrical resistivity, and the flexural strength of the baked core samples were determined based on ASTM D5502-00 (2015), ASTM D6120-97(2012), and ISO N848, respectively. Then, two samples of $50 \mathrm{~mm}$ height were cut from the top and the bottom of the baked cores, maintaining the position the same for all anodes. The sample from the top was used for the air reactivity measurement according to ASTM-D6559-00a, and the sample from the bottom was used for the $\mathrm{CO}_{2}$ reactivity measurement following ASTM-D6558-00a. The dusting during the tests was also recorded for the reactivity studies. 


\section{Results and discussion}

\subsection{Properties of biocoke}

\subsubsection{Real density}

Figure 1 shows the effect of the heating rate and the maximum temperature during calcination on the carbon real density of the biocokes. The real density of the bio-char was taken as 1 (as the reference) to see the improvement in the biocoke real densities. Further calcination of the bio-char (BCA) to $1200{ }^{\circ} \mathrm{C}$ (BCO-5) improved the real density. The impact of the heating rate can also be seen clearly in this figure. The slower the heating rate is, the higher the reals density is. Thus, increasing the maximum temperature and reducing the heating rate likely increase the real density of the resultant biocoke.

The density of raw material influences significantly the anode quality. Since BCO-1 gave the highest real density, this biocoke was chosen to produce anodes. The same calcination conditions were used to produce large amounts biocoke in a lab furnace as explained previously.

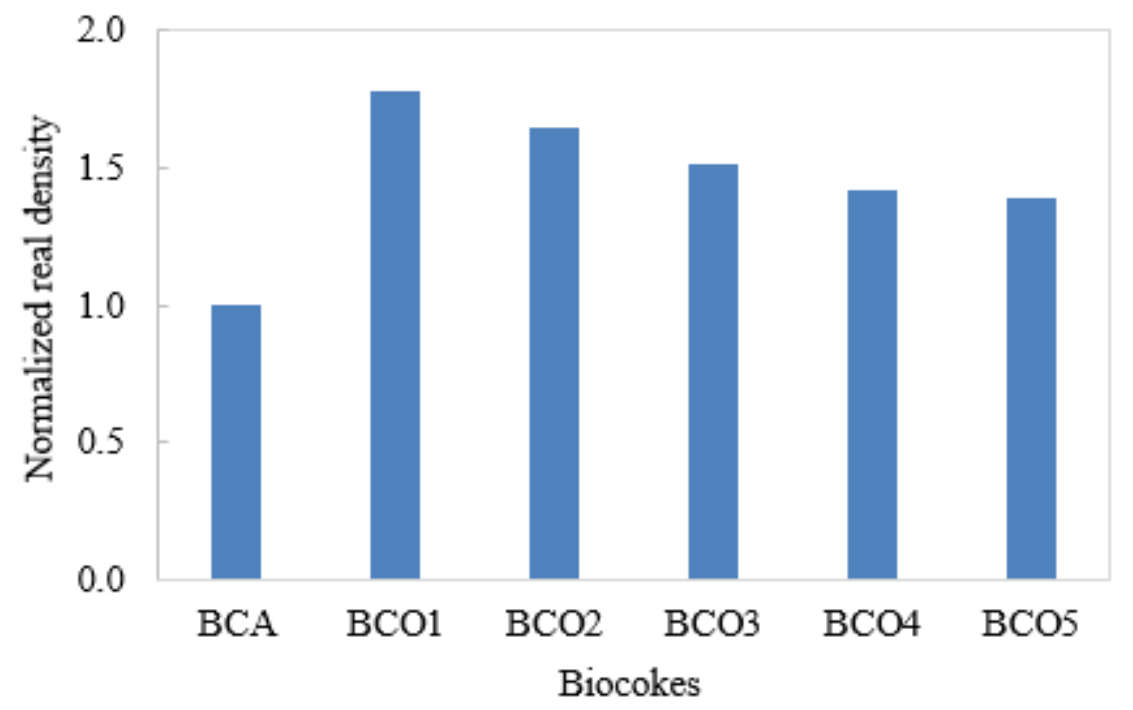

Figure 1 Effect of heating rate and maximum temperature on the real density of biocokes

(presented relative the real density of bio-char taken as 1)

\subsubsection{Microstructure}

This work focuses on the effect of the percentage of biocoke added and the particle size on anode properties. Therefore, the structure of biocoke with different sizes was investigated using SEM. Figure 2 shows the SEM images of the biocoke with different particle sizes and the petroleum coke. The larger biocoke particles have a greater amount of large pores originating from the nature of the cell structure of woody materials (Figure 2 (a,d)). As for the biocoke with particle sizes less than $45 \mu \mathrm{m}$ (Figure 2 (b,e)), the larger 
pores have been destroyed during the crushing process. The appearance of these fine biocoke particles is similar to that of the petroleum coke particles of the same size fraction as shown in Figure 2 (c,f). This similarity in structure and in appearance of the fine particles of biocoke and petroleum coke allows the substitution of a certain percentage of petroleum coke by biocoke.
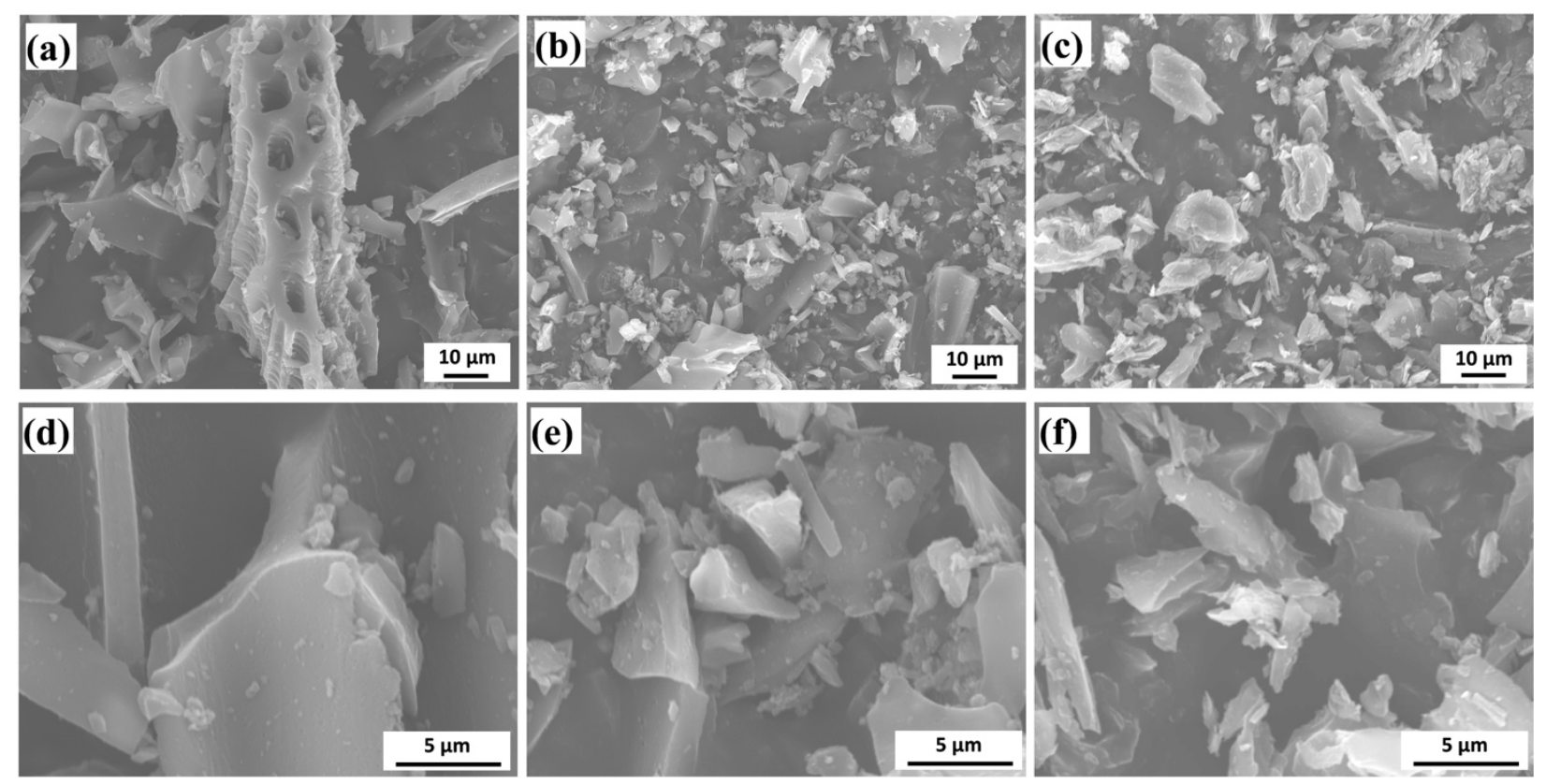

Figure 2 SEM images: biocoke particles of sizes less than (a,d) $125 \mu \mathrm{m}$ and (b,e) $45 \mu \mathrm{m}$; (c,f) petroleum coke particles of sizes less than $45 \mu \mathrm{m}$

Table 2 shows the comparison of the composition of biocoke and petroleum coke measured by EDS. The oxygen contents are significantly different, and biocoke has much more oxygen than petroleum coke. The excess oxygen would likely be removed during the anode baking process. If it remains in anode, it may adversely affect the resultant anode quality. Bio-coke has a much lower sulfur content, which would lower the $\mathrm{SO}_{2}$ emissions and consequently reduce the environmental impact.

Table 2 Composition of different elements of biocoke and petroleum coke $(<45 \mu \mathrm{m})$

\begin{tabular}{|c|c|c|}
\hline Element & Petroleum coke (wt\%) & Biocoke $(\mathrm{wt} \%)$ \\
\hline $\mathrm{C}$ & 96.62 & 92.97 \\
\hline $\mathrm{O}$ & 1.94 & 6.40 \\
\hline $\mathrm{S}$ & 1.45 & 0.63 \\
\hline
\end{tabular}




\subsubsection{BET surface area}

The surface areas of biocoke and petroleum coke were determined by the BET method. The values of single and multiple-point specific surface area, total pore volume, and average pore diameter were measured, and the results are shown in Table 3.

Table 3 Pore characteristic parameters of biocoke and petroleum coke from BET test

\begin{tabular}{|l|c|c|c|c|}
\hline \multicolumn{1}{|c|}{ Coke sample } & $\begin{array}{c}\text { Single point } \\
\text { specific surface } \\
\text { area }\left(\mathrm{m}^{2} / \mathrm{g}\right)\end{array}$ & $\begin{array}{c}\text { BET multiple- } \\
\text { point specific } \\
\text { surface area }\left(\mathrm{m}^{2} / \mathrm{g}\right)\end{array}$ & $\begin{array}{c}\text { Total pore } \\
\text { volume } \\
\left(\mathrm{cm}^{3} / \mathrm{g}\right)\end{array}$ & $\begin{array}{c}\text { Average } \\
\text { pore diameter } \\
(\AA)\end{array}$ \\
\hline Biocoke $(2-4 \mathrm{~mm})$ & 24.136 & 24.141 & 0.031 & 51.319 \\
\hline Biocoke $(<45 \mu \mathrm{m})$ & 34.971 & 35.398 & 0.051 & 57.718 \\
\hline Petroleum coke $(<45 \mu \mathrm{m})$ & 3.449 & 3.601 & 0.047 & 523.441 \\
\hline
\end{tabular}

It can be observed from Table 3 that the values for the specific surface area of biocoke are significantly higher than that of petroleum coke. Crushing sample to finer particles for biocoke increases its specific surface area. However, the total pore volume of the three samples are close. The measured average pore diameter in petroleum coke was almost ten times those for biocoke. The high specific surface area and the low pore diameter results indicate the abundance of micropores in biocoke. It is more difficult for viscous pitch to penetrate into the micropores of biocoke than those of petroleum coke with larger pores. High specific surface area may also favor more chemical reactivity with $\mathrm{CO}_{2}$ and air.

\subsubsection{FTIR analysis}

The surface chemical structures of biocoke and petroleum coke were investigated by the FTIR spectroscopy. Figure 3 shows the comparison of FTIR spectra of the biocoke and the petroleum coke. Upon analysis of the spectra, the results show that the surface chemical composition of biocoke is different in nature compared to that of petroleum coke. This is in agreement with the FTIR result of a previous work [16]. The surface functional groups such as $\mathrm{C}-\mathrm{OH}, \mathrm{COOH}$, and some alkyl groups of petroleum cokes play a key role in the chemical activation process [21]. The most notable difference in the spectra of biocoke and petroleum coke is in the band at $3500 \sim 3200 \mathrm{~cm}^{-1}$, which pertains to heteroatoms containing groups such as amines ($\mathrm{NH})$, hydroxyl groups (-OH), carboxyl groups (-COOH), carbonyl group $(\mathrm{C}=\mathrm{O})$, and C-O groups [16]. Biocoke has a large peak for this band including chemically active groups, and this may result in a more reactive carbon anode material compared to petroleum coke. There is no significant difference in other bands for these two cokes. 


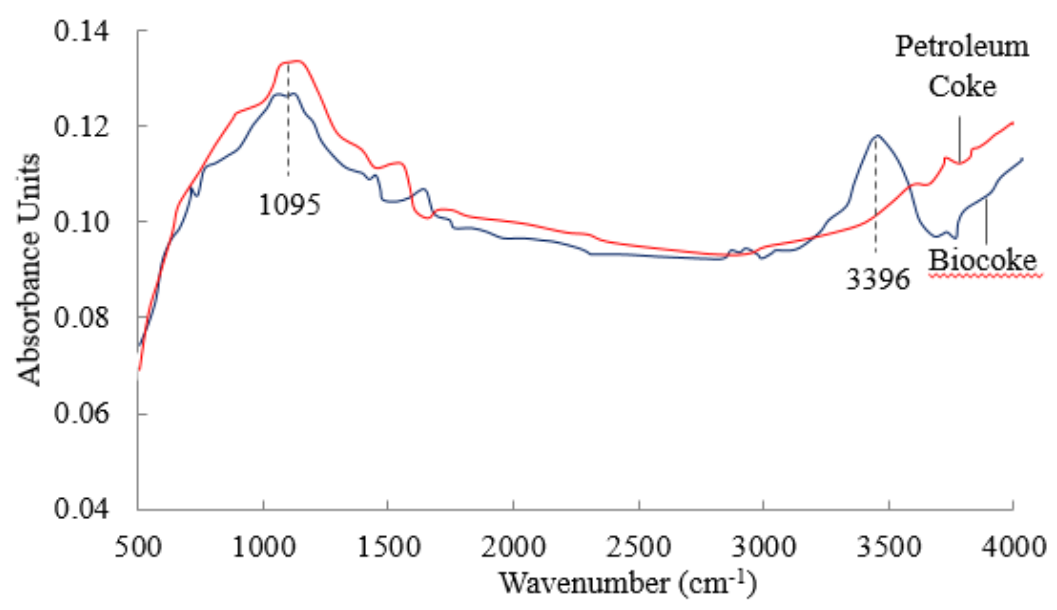

Figure 3 Comparison of the FTIR spectra of petroleum coke and biocoke

\subsubsection{Raman Spectroscopy}

The characterization of carbonaceous materials using Raman spectroscopy is reported in a large number of studies [2, 5, 7, 19, 20]. Carbonaceous materials can exhibit up to five characteristic Raman spectra bands (see Table 4) [19]. For graphite carbon materials, the $G$ band located at $1600 \mathrm{~cm}^{-1}$ is the most prominent band, which represents the vibration of the ideal graphite lattice. Other four bands indicate disordered graphitic lattice.

Table 4 Characteristic Raman spectra bands of carbonaceous materials [19]

\begin{tabular}{|c|c|l|}
\hline Bands & Position $\left(\mathrm{cm}^{-1}\right)$ & \multicolumn{1}{|c|}{ Represent } \\
\hline$G$ & 1600 & Vibration of the ideal graphite lattice $\left(\mathrm{E}_{2 \mathrm{~g}}\right.$ symmetry $)$ \\
\hline D1 & 1350 & Vibration of graphene layer edges $\left(\mathrm{A}_{1 \mathrm{~g}}\right.$ symmetry) \\
\hline D2 & 1650 & Vibration of surface graphene layers $\left(\mathrm{E}_{2 \mathrm{~g}}\right.$ symmetry) \\
\hline D3 & 1500 & Vibration of amorphous regions \\
\hline D4 & 1220 & Local disorder by the presence of ionic impurities \\
\hline
\end{tabular}

Relevant bands typical of carbonaceous materials were fitted to pseudo-Voigt line shapes, and relative widths and intensities were calculated. Figure 4 shows the Raman spectra of biocoke and petroleum coke studied presenting the results of the least squares fitting to five peaks on the positions described above. It can be found that the relative intensities of the G to D1 bands for petroleum coke are higher than those of biocoke. 

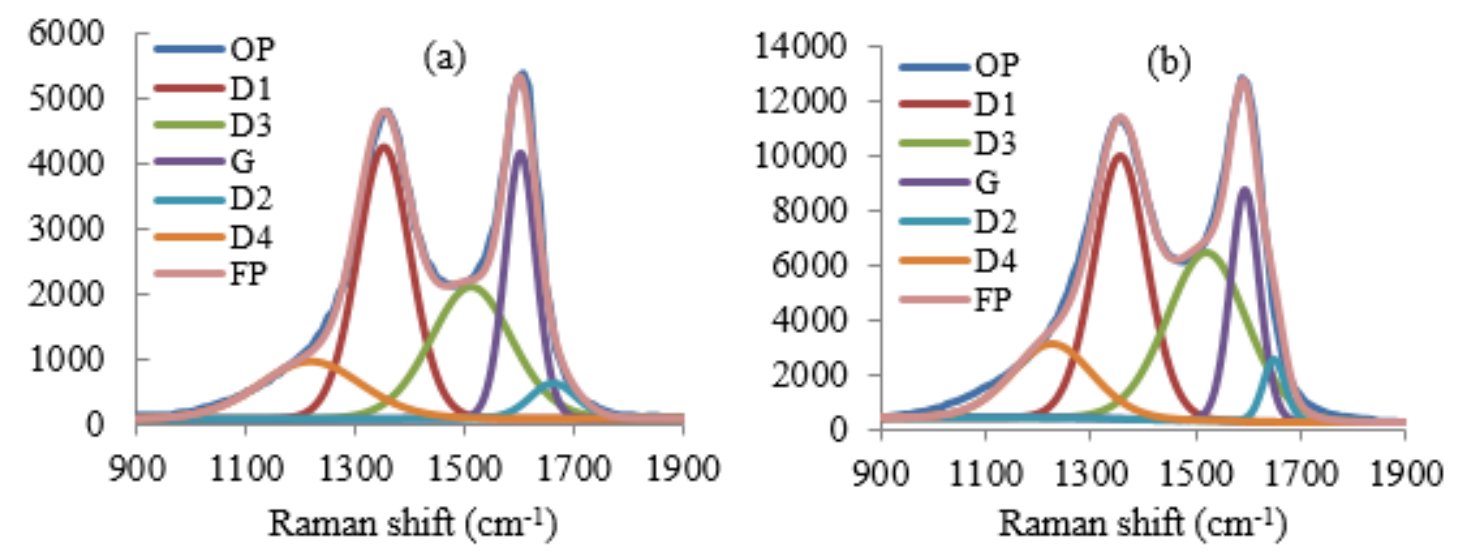

Figure 4 Raman spectra as well as peak fitting results for (a) petroleum coke and (b) biocoke (OP denotes Original Peak and FP denotes Fitted Peak)

The actual full width at half maximum (FWHM) and the position of the five bands for the two samples studied are presented in Table 5. The larger FWHM of the G band in biocoke indicates a lower amount of graphitic carbon in relation to amorphous carbon and therefore a lower of structural order in the material. The smaller G/D1 ratio confirms the less ordered graphite structure of biocoke and more amorphous carbon. To further quantify this effect, the extent of structural order in the graphitized carbon scaffolds was assessed by calculating the degree of crystallinity R defined as the relative fraction of the G-band intensity to the sum of the intensities of bands $\mathrm{G}$ and $\mathrm{D}_{1}$, according to the following equation:

$$
R=\frac{I_{G}}{I_{D 1}+I_{G}}
$$

This parameter is given in Table 5. It can be seen that there is biocoke has a slightly lower crystallinity degree than petroleum coke. This lower crystalline carbon structure in biocoke results in its week mechanical strength and high chemical reactivity.

Table 5 Peak positions and line widths of Raman bands for biocoke and petroleum coke

\begin{tabular}{|c|c|c|c|c|c|c|c|c|c|c|c|c|}
\hline \multirow{2}{*}{ Sample } & \multicolumn{2}{|c|}{ D4 } & \multicolumn{2}{c|}{ D1 } & \multicolumn{2}{c|}{ D3 } & \multicolumn{2}{c|}{ G } & \multicolumn{2}{c|}{ D2 } & \multirow{2}{*}{ G } \\
\cline { 2 - 13 }$n n$ \\
\hline $\begin{array}{c}\text { Petroleum } \\
\text { coke }\end{array}$ & 219.11 & 1218.38 & 115.00 & 1352.59 & 175.00 & 1512.72 & 65.00 & 1603.16 & 100.00 & 1663.29 & 0.36 & 0.57 \\
\hline Biocoke & 180.03 & 1226.00 & 120.00 & 1356.16 & 180.00 & 1520.78 & 67.00 & 1593.96 & 50.00 & 1649.76 & 0.32 & 0.47 \\
\hline
\end{tabular}

3.2. Effect of biocoke addition on the properties of resultant anodes

\subsubsection{Appearance of anodes}

Images in Figure 5 show the appearance of the resultant green anodes (with and without the addition of biocoke) on their vertical surfaces. The values 1\%, 3\%, and 5\% in Figure 5 (b), (c), and (d) correspond to 
percentages of biocoke added with particles sizes less than $125 \mu \mathrm{m}$. The letter F in Figure 5 (e) indicates fine particles; that is, in this case, $3 \%$ of the petroleum coke was replaced by biocoke with particle sizes less than $45 \mu \mathrm{m}$. Since the resultant anodes are black and look similar, it is difficult to observe the biocoke particles in the anodes regardless of the bio-material proportion. It is worthwhile to mention that the top corners of only the anode with 5\% biocoke replacement were damaged during handling. This may be the indication of lower mechanical strength for this anode compared to other anodes.

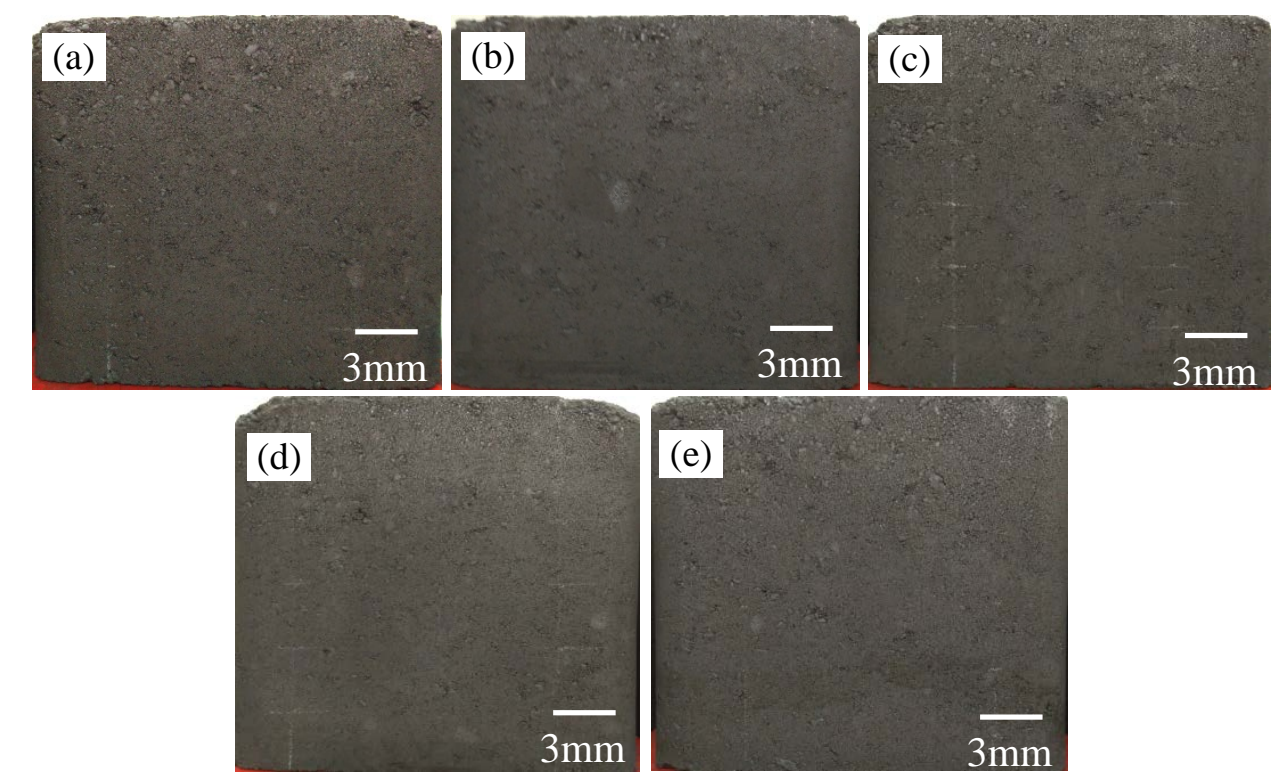

Figure 5 Appearance of anodes: (a) Standard, (b) 1\%, (c) 3\%, (d) 5\%, (e) 3\%F (F indicates the addition of biocoke with particle sizes less than $45 \mu \mathrm{m}$ compared to particle sizes less than $125 \mu \mathrm{m}$ for (b), (c), (d))

\subsubsection{Electrical resistivity}

The electrical resistivity is a critical parameter for anode quality because it is directly linked to energy consumption during electrolysis. The higher porosity and the lower crystalline structure of biocoke may adversely influence the anode properties. Thus, the addition of biocoke may lead to lower density and higher electrical resistivity in anodes. The electrical resistivity distributions in the green anodes produced were measured using the SERMA technology developed at UQAC [18]. It helps determine the electrical resistivities between two surfaces at a number of positions in two directions (between top and bottom surfaces and two side surfaces). The detailed information about the equipment and the measurement procedure has been given elsewhere [22]. The results show the resistivity mapping in the two directions of measurement.

The images in Figure 6 show the electrical resistance distributions of the green anodes in two directions. The red color refers to high resistivity and blue means low resistivity. As can be seen from this figure, there 
is a good correspondence between the resistivity of anodes and the biocoke percentage added. For the biocoke addition with particle sizes less than $125 \mu \mathrm{m}$ (Figure 6 (b), (c), (d)), the resistivities tend to increase as the biocoke percentage increases, and they are higher than those of the standard anode (Figure 6 (a)). This means the addition of biocoke using relatively coarse particles causes an increase in the resistivity due to lower bulk density and greater micropore presence leading to lower conductivity compared to the more graphitic structure of petroleum coke particles.

The intersections of the highly resistive regions in two directions show the position of defective regions in the anode. For the anode produced with the addition of finer biocoke particles (Figure 6 (e), particle size less than $45 \mu \mathrm{m}$ ), the resistivities are lower in comparison to the other anodes made with larger biocoke particles. This anode also displays a resistivity distribution similar to that of the standard anode. The finer particles have lower porosity and thus decrease the porosity and consequently the electrical resistivity. Also, the resistivity distribution in both directions is more uniform

(a)

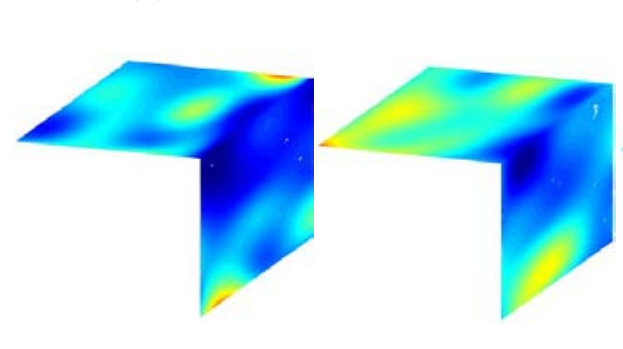

(c)

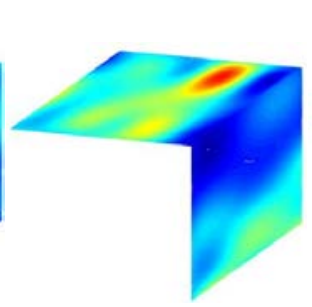

(d)

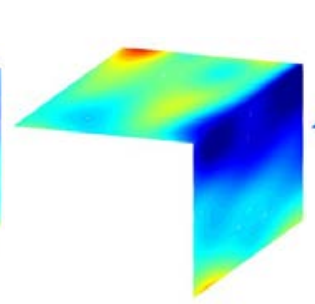

(e)

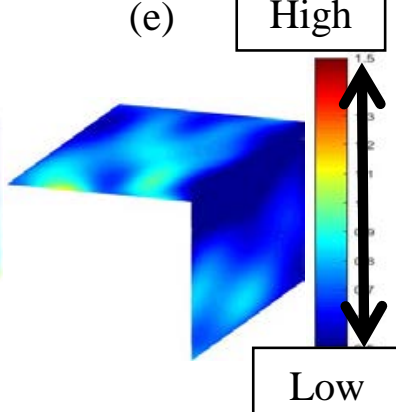

Figure 6 Electrical resistivity distribution of green anodes in two directions:
(a) Standard,
(b) $1 \%$
$\%$, (c) $3 \%$,
(d) $5 \%$, (
(e) $3 \% \mathrm{~F}$

The electrical resistivities of the green and baked standard core samples were measured and are presented in Figure 7. The green core resistivities (Figure 7 (a)) showed the same tendency that was observed above for the entire green anodes. The electrical resistivity of green anode cores increased with the coarse biocoke particle addition of $1 \%$ to $5 \%$. Their resistivities are greater than that of the standard anode made with petroleum coke only. The resistivity for baked anode cores (Figure 7 (b)) showed the same trend. Biocoke with lower crystallinity and porosity compared to the petroleum coke in this particle size range resulted in higher electrical resistivity for green and baked anodes.

However, the anode made with 3\% fine biocoke particle addition shows electrical resistivity values comparable to those of the standard anode. This can possibly be explained by the elimination of large pores during crushing. Therefore, the addition of finer biocoke particles in making anodes seems to diminish the detrimental influence of porosity on anode resistivity. The use of very fine particle may favor the acceptance of biocoke as raw material to produce carbon anodes due to similar electrical resistivities. 

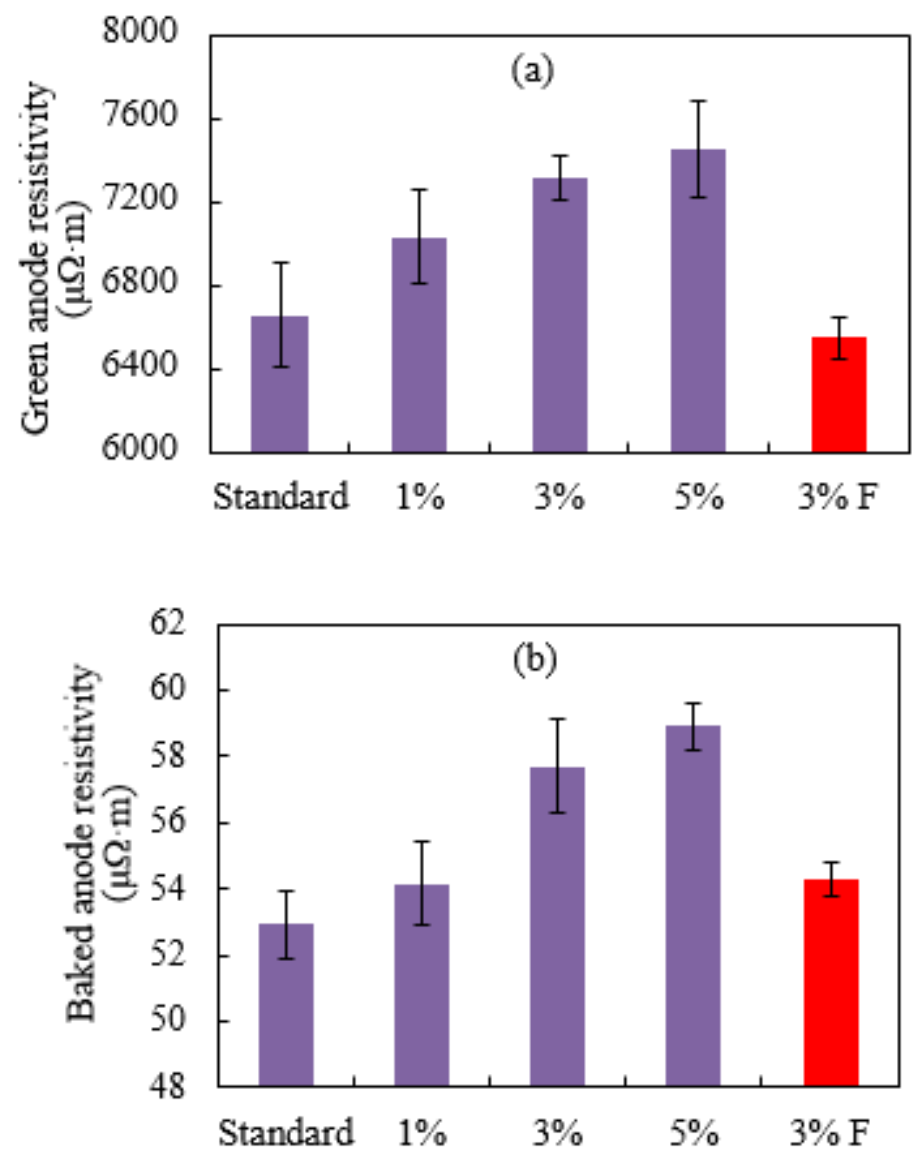

Figure 7 Electrical resistivity of (a) green anode cores and (b) baked anode cores

\subsubsection{Density of green and baked anode}

Density of a green or a baked anode is a good indicator for its quality. A good quality anode requires high green and baked anode densities. Figure 8 shows the densities of green and baked anode cores for the five anodes. It can be seen from Figure 8 (a) and (b) that both green and baked densities follow the same trend. Densities of the anodes containing coarse biocoke particles decrease as the biocoke percentage increases from 3\% to 5\%. It was observed from the above SEM results (Figure 2) that larger biocoke particles have higher porosity. This pore structure reduces the bulk density of resultant anode. When the biocoke was crushed to finer particles, the larger pore structure was destroyed. The anode made with finer biocoke particle addition has similar (even slightly higher in the case of baked anode) densities compared to the standard anode. Therefore, the utilization of finer biocoke particles helps eliminate its adverse impact on density. 

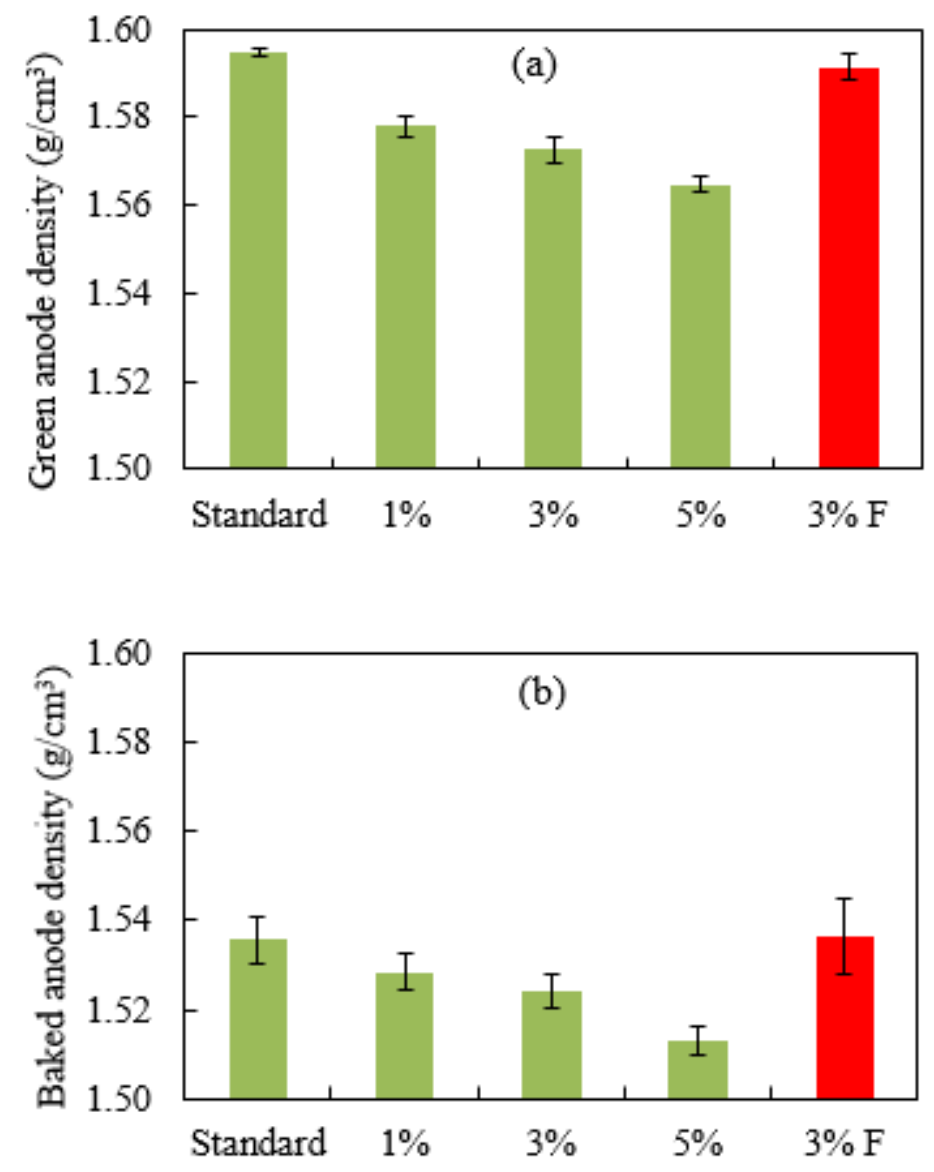

Figure 8 Density of (a) green anodes and (b) baked anodes

\subsubsection{Flexural Strength}

The three-point bending test was carried out to measure the flexural strength of the anodes. The characterization results indicate that biocoke is structurally weaker than petroleum coke. Thus, the addition of biocoke may lower the mechanical strength of resultant anodes. Ng and his co-workers [23] reported the incorporation bio-char particles played a critical role in determination of the mechanical properties of resultant biocoke in ironmaking process. It was found that adding $5 \%$ coarse bio-char to coal blend reduced significantly the strength and the hardness of the resultant coke while blending with fine bio-char particles did not show much change in the mechanical properties. These findings are in agreement with the results of this study. As can be seen in Figure 9, the flexural strength of the anodes produced using 1\% and 3\% coarse biocoke particles was slightly lower than that of the standard anode. However, the addition of 5\% coarse biocoke particles reduced the flexural strength significantly, accompanying with a big standard error bar between test samples. The anode made with 3\% finer biocoke particles had a similar flexural strength to the standard anode. 


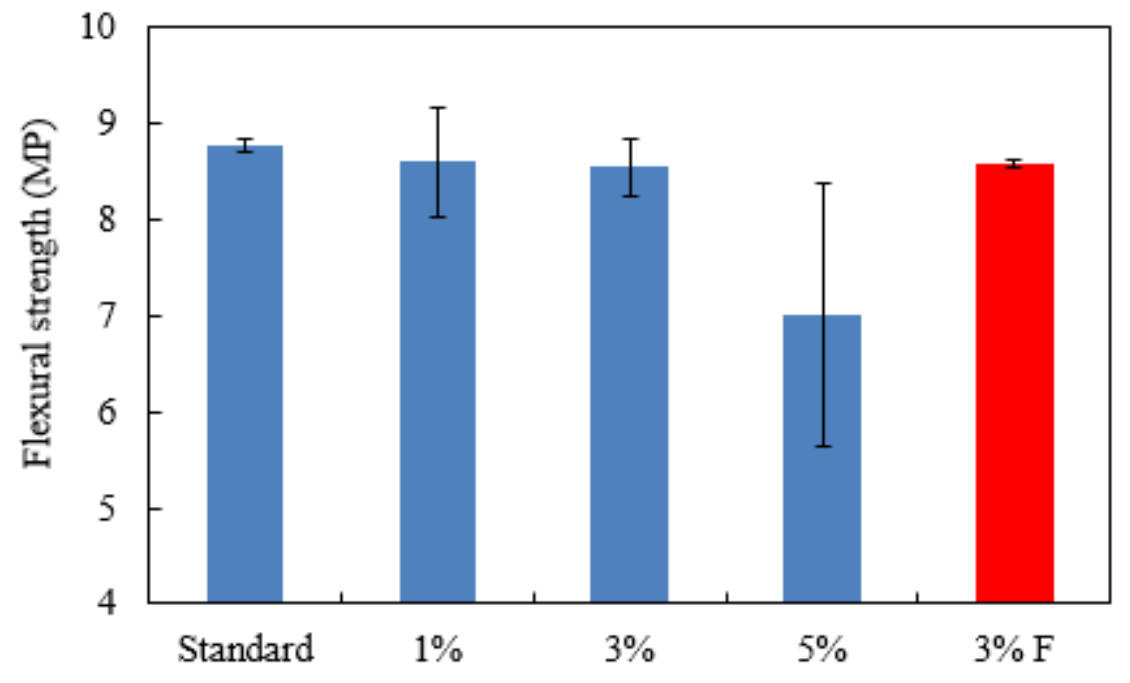

Figure 9 Flexural strength of anodes

\subsubsection{Reactivity with air and carbon dioxide}

Carbon acts as a reductant to reduce alumina to aluminum and is oxidized to $\mathrm{CO}_{2}$ during the electrolytic production of aluminum. Carbon is further consumed due to undesirable secondary reactions. The $\mathrm{CO}_{2}$ gas that forms at the anode/electrolyte interface can react with the carbon in anode and form CO in the cell $\left(\mathrm{CO}_{2}\right.$ reactivity). Since the top part of the side surface of anode is exposed to air, carbon can react with $\mathrm{O}_{2}$ to form $\mathrm{CO}_{2}$ at temperatures above $\approx 450{ }^{\circ} \mathrm{C}$ (air reactivity). Also, Pitch coke (carbonized pitch) is usually more reactive than calcined coke. This difference in reactivity results in greater consumption of the binder between the coke particles. Consequently, the coke particles fall into the electrolytic bath due to the loss of structural integrity, and this is called dusting. These secondary reactions result in excess carbon consumption. The reactivity of anode is related to this excess anode consumption which results in the emission of additional greenhouse gases. 


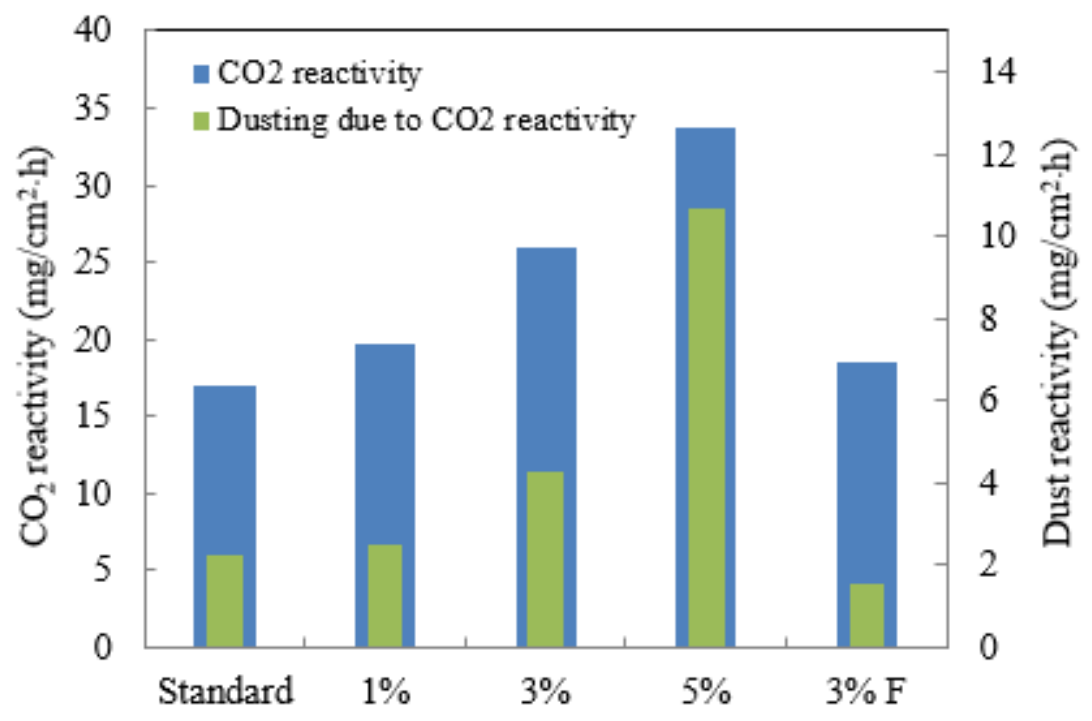

Figure $10 \mathrm{CO}_{2}$ reactivity and dusting of anodes

Biocoke is usually more chemically reactive and thus it is likely to be consumed more rapidly compared to calcined coke and pitch coke. To evaluate the impact of biocoke addition on reactivities, the $\mathrm{CO}_{2}$ and air reactivities were measured in a TGA. Figure 10 shows the $\mathrm{CO}_{2}$ reactivities and corresponding dusting of anodes. This reactivity increases as the percentage of coarse biocoke particle addition increases. However, the anode made with 3\% finer biocoke particles has a lower $\mathrm{CO}_{2}$ reactivity than those of anodes with coarse biocoke particles; and its $\mathrm{CO}_{2}$ reactivity is similar to that of the standard anode. This agrees with the result reported for the utilization of bio-char in making biocoke for ironmaking [23]. Addition of char finer than $0.07 \mathrm{~mm}$ influences slightly the $\mathrm{CO}_{2}$ reactivity of the resultant biocoke while the coarse char increases dramatically its reactivity.

Anode air reactivity is strongly related to its density and porosity (higher anode density implies the presence of lower porosity). Air reacts with any carbon material if the temperature is high enough, and the reactivity can increase as the anode density increases [24]. Figure 11 presents the air reactivities and corresponding dusting of the anodes produced, and they are all within the same range. The reactivities of anodes with $1 \%$ and 3\% coarse biocoke addition are close to that of the standard anode while the anode made with 5\% coarse biocoke displays a notably lower reactivity. The anode produced with 3\% finer biocoke particles also has low air reactivity. This reduction in air reactivity might be due slightly lower density (and higher porosity) on the anode surface. Further study is required to draw more conclusive results and to determine the mechanism. 


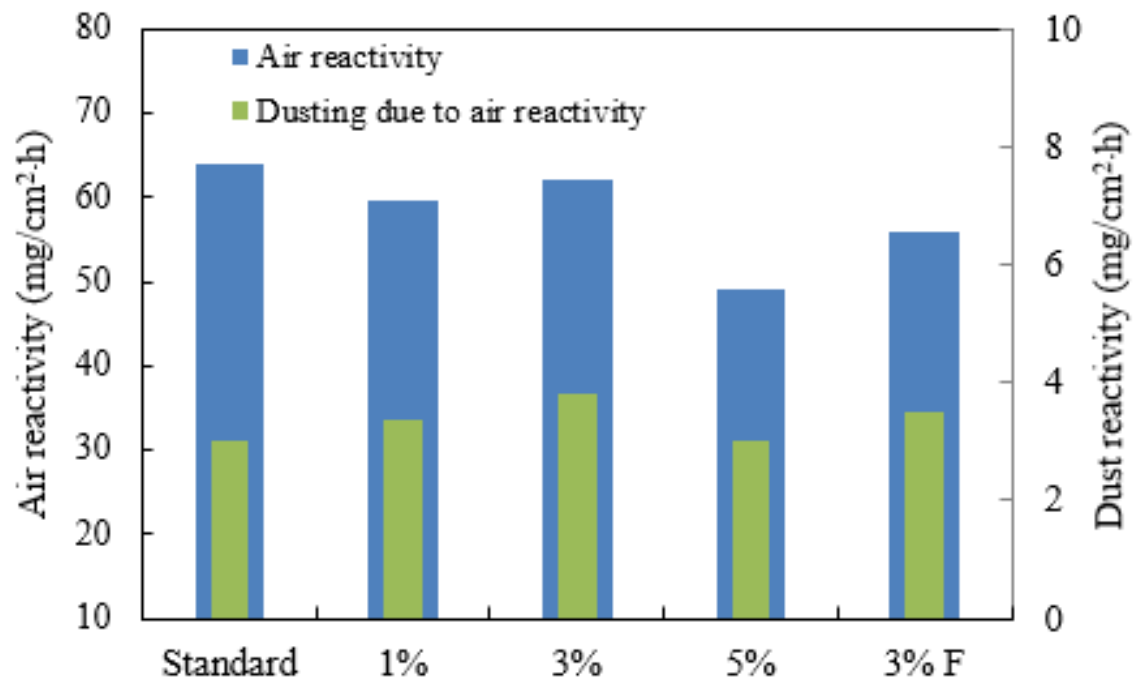

Figure 11 Air reactivity and dusting of anodes

\section{Conclusions}

The use of biocoke as the raw material in making anodes would reduce the greenhouse gas emissions. Higher porosity and lower structural strength of biocoke affect the anode properties adversely. To address this challenge, first a study on the calcination parameters (heating rate and maximum temperature) was conducted to determine the conditions for the production of biocoke with better properties. Lower heating rate and higher maximum temperature were found to improve biocoke real density. Anodes were produced using the biocoke with the highest real density. Three anodes were made by replacing a certain percentage $(1 \%, 3 \%, 5 \%)$ of petroleum coke with biocoke of less than $125 \mu \mathrm{m}$ particles, and one anode was produced with the replacement of $3 \%$ biocoke with particles of less than $45 \mu \mathrm{m}$. Their properties were compared with those of the standard anode. The anode made with finer particle size biocoke had properties similar to those of the standard anode; thus, the recipe developed could be used in replacing part of the petroleum coke by biocoke for the reduction of greenhouse gas emissions from smelters while maintaining the anode quality at the desired level. Additional work is needed to determine if the percentage of petroleum coke that can be replaced by biocoke can be increased beyond 3\% by improving biocoke properties further.

\section{Acknowledgments}

The authors would like to thank University of Quebec at Chicoutimi and Natural Sciences and Engineering Research Council of Canada for their financial contributions. The authors also thank the technician $s$ in CRUAL research center, for their technical support in anode making and SEM analysis.

\section{Reference:}


[1] A. Arenillas, F. Rubiera, C. Pevida, C.O. Ania, J.J. Pis, Relationship between structure and reactivity of carbonaceous materials, J Therm Anal Calor 76 (2004) 593-602.

[2] M. Asadullah, S. Zhang, Z. Min, P. Yimsiri, C.-Z. Li, Effects of biomass char structure on its gasification reactivity, Bioresource Technology 101 (2010) 7935-7943.

[3] E. Iniesta, F. Sánchez, A.N. García, A. Marcilla, Yields and CO2 reactivity of chars from almond shells obtained by a two heating step carbonisation process. Effect of different chemical pre-treatments and ash content, J Anal Appl Pyrolysis 58-59 (2001) 983-994.

[4] A.K. Kercher, D.C. Nagle, Microstructural evolution during charcoal carbonization by X-ray diffraction analysis, Carbon 41 (2003) 15-27.

[5] X. Li, J.i. Hayashi, C.Z. Li, FT-Raman spectroscopic study of the evolution of char structure during the pyrolysis of a Victorian brown coal, Fuel 85 (2006) 1700-1707.

[6] L. Lu, C. Kong, V. Sahajwalla, D. Harris, Char structural ordering during pyrolysis and combustion and its influence on char reactivity, Fuel 81 (2002) 1215-1225.

[7] Y. Wang, D.C. Alsmeyer, R.L. McCreery, Raman spectroscopy of carbon materials: Structural basis of observed spectra, Chemistry of Materials 2 (1990) 557-563.

[8] A. Hussein, M. Fafard, D. Ziegler, H. Alamdari, Effects of Charcoal Addition on the Final Properties of Carbon Anodes, ICSOBA2016 (2016).

[9] A.R. Coutinho, J.D. Rocha, C.A. Luengo, Preparing and characterizing biocarbon electrodes, Fuel Processing Technology 67 (2000) 93-102.

[10] Y. Li, Y.S. Hu, M.M. Titirici, L. Chen, X. Huang, Hard Carbon Microtubes Made from Renewable Cotton as High-Performance Anode Material for Sodium-Ion Batteries, Advanced Energy Materials 6 (2016).

[11] P. Wang, B. Qiao, Y. Du, Y. Li, X. Zhou, Z. Dai, J. Bao, Fluorine-Doped Carbon Particles Derived from Lotus Petioles as High-Performance Anode Materials for Sodium-Ion Batteries, Journal of Physical Chemistry C 119 (2015) 21336-21344.

[12] P. Wang, X. Zhu, Q. Wang, X. Xu, X. Zhou, J. Bao, Kelp-derived hard carbons as advanced anode materials for sodium-ion batteries, Journal of Materials Chemistry A 5 (2017) 5761-5769.

[13] Q. Wang, X. Zhu, Y. Liu, Y. Fang, X. Zhou, J. Bao, Rice husk-derived hard carbons as highperformance anode materials for sodium-ion batteries, Carbon 127 (2018) 658-666.

[14] X. Huang, D. Kocaefe, D. Bhattacharyay, Y. Kocaefe, MOrphological and microstructural characterization of bio-coke as potential anode raw material for aluminum industry, Materials Science and Technology Conference and Exhibition 2013, MS and T 2013, 2013, pp. 1057-1064.

[15] X. Huang, D. Kocaefe, Y. Kocaefe, D. Bhattacharyay, Interaction of bio-coke with different coal tar pitches, Fuel 179 (2016) 179-192. 
[16] X. Huang, D. Kocaefe, Y. Kocaefe, D. Bhattacharyay, Wettability of bio-coke by coal tar pitch for its use in carbon anodes, Colloids and Surfaces A: Physicochemical and Engineering Aspects 490 (2016) 133-144.

[17] X.A. Huang, D. Kocaefe, D. Bhattacharyay, Y. Kocaefe, B. Morais, Characterization of carbon anode materials by image analysis, TMS Light Metals, 2016, pp. 859-864.

[18] A. Gutiérrez-Pardo, J. Ramírez-Rico, R. Cabezas-Rodríguez, J. Martínez-Fernández, Effect of catalytic graphitization on the electrochemical behavior of wood derived carbons for use in supercapacitors, $\mathrm{J}$ Power Sources 278 (2015) 18-26.

[19] J. Ramirez-Rico, A. Gutierrez-Pardo, J. Martinez-Fernandez, V.V. Popov, T.S. Orlova, Thermal conductivity of Fe graphitized wood derived carbon, Materials \& Design 99 (2016) 528-534.

[20] S.I. Masao Matsuoka, Ronaldo D. Mansano, Wilmer Sucasaire, Ricardo A. C. Pinto, Juan C. R. Mittani, Kiyoshi Ogata, Naoto Kuratani X-Ray Photoelectron Spectroscopy and Raman Spectroscopy Studies on Thin Carbon Nitride Films Deposited by Reactive RF Magnetron Sputtering, World Journal of Nano Science and Engineering 2(02) (2012) 92-102.

[21] V.G. Rocha, C. Blanco, R. Santamaría, E.I. Diestre, R. Menéndez, M. Granda, An insight into pitch/substrate wetting behaviour. The effect of the substrate processing temperature on pitch wetting capacity, Fuel 86 (2007) 1046-1052.

[22] A. Benzaoui, D. Kocaefe, D. Bhattacharyay, Y. Kocaefe, A non-destructive technique for the on-line quality control of green and baked anodes, Metals 7 (2017).

[23] K.W. Ng, L. Giroux, T. MacPhee, T. Todoschuk, Incorporation of charcoal in coking coal blend - A study of the effects on carbonization conditions and coke quality, AISTech - Iron and Steel Technology Conference Proceedings, 2012, pp. 225-236.

[24] S. Ozturk, D. Kocaefe, D. Bhattacharyay, Y. Kocaefe, B. Morais, Modification of coke by different additives to improve anode properties, Fuel 211 (2018) 102-109. 